\title{
COMPARATIVE STUDY OF EVALUATION OF SENSITIVITY AND SPECIFICITY OF CYTOLOGY AND COLPOSCOPY FOR DETECTION OF PRECANCEROUS LESIONS OF CERVIX
}

S. Sharma ${ }^{1}$, A. Sharma ${ }^{2}$ U. Sinha ${ }^{3}$, Roshan Chanchlani ${ }^{4}$

HOW TO CITE THIS ARTICLE:

S. Sharma, A. Sharma, U. Sinha, RoshanChanchlani. "Comparative Study Of Evaluation Of Sensitivity And Specificity Of Cytology And Colposcopy For Detection Of Precancerous Lesions Of Cervix". Journal Of Evolution Of Medical And Dental Sciences 2013; Vol2, Issue 50, December 16; Page: 9697-9701.

ABSTRACT: BACKGROUND:Cervical cancer is the second most common cancer among women globally and a leading cause of death due to cancer among women. If diagnosed earlier, it has a high cure rate but advanced disease is frequently incurable with very unpleasant consequences. MATERIAL AND METHODS: This was a cross sectional study done on a group of 50 women. A detailed clinical history of each patient was taken. The patients were made to lie in dorsal lithotomy position and per speculum examination was done. After evaluating the cervix, Paps smear was taken for cytology with Ayers spatula from ectocervix after rotating at 360 degree and spread on 2 glass slides to prepare thin films and kept in koplin jar and sent for cytology reporting. The patients were then subjected to colposcopy and punch biopsy. RESULTS: On comparison with biopsy cervix as gold standard for detection of CIN, cytology had shown Sensitivity - 57.14\%, Specificity - 88.88\%, NPV84.21\%, PPV - 66.66\%, whereas colposcopy had shown Sensitivity - 80\%, Specificity - 80\%, NPV 94.11\%, PPV - 50\%. CONCLUSION:In developing countries like India, cytology, a low cost and easily accessible test, is the most logical screening modality although it has very low sensitivity but detection rates could be further improved using liquid cytology and use of endocervicalcytobrush. Colposcopy with high sensitivity is although an important adjunctive screening modality but requires expertise and training for interpretation and is costly.

KEY WORDS: Biopsy,Colposcopy, Cervical cancer, CIN, Cytology, Pre-cancerous lesion.

INTRODUCTION: Cervical cancer is the second most common cancer among women globally and a leading cause of death due to cancer among women. ${ }^{1}$ Out of 233,000 women who died each year due to cervical cancer, majority were from developing countries. ${ }^{2}$ In India, it is the most common malignancy according to National Cancer Registry Program, 1988-89 report. The reported incidence of preclinical invasive carcinoma in India is around is $1.5 / 1,000 .{ }^{3}$ When it presents or is discovered early, it has a high cure rate but advanced disease is frequently incurable with very unpleasant consequences. Thus, prevention of cervical cancer is regarded as a very sensitive and important public health issue.

It is estimated that every year about 90,000 new cases arise in India. In western countries, cervical cancer incidence and deaths have been brought under control using organized cytology screening programmes. In developing countries including India, due to other compelling health problems as control of infectious diseases and population explosion, it is not possible to launch nationwide cytology screening programmes for cervical cancer.

Epidemiological studies have consistently shown the central importance of sexual behavior (early age of first sexual intercourse, multiple sexual partners) in the origin of precursor lesions and 


\section{ORIGINAL ARTICLE}

invasive cervical cancer indicating that a sexually transmissible agent causes these conditions. Indeed, there is now compelling epidemiologic and molecular evidence that cervical infection with HPV (human papilloma virus) causes cervical neoplasms and is present in $99.7 \%$ cases of cervical cancer. 3,4

Screening modalities used for cervical cancer are cytology, colposcopy, visual inspection of cervix after application of lugol's iodine and acetic acid, HPV DNA testing and education and awareness campaign.

In our study, we intend to compare sensitivity and specificity of cytology and colposcopy in diagnosis of precursor lesions of cervical cancer with biopsy as a gold standard so that recommended screening modalities could be justified.

MATERIAL AND METHODS: This was a cross sectional study conducted in department of obstetrics \&gynaecology, Chirayu medical college, Bhopal from January 2011- June 2012. 50 Womenof ages between 20- 60 years attending gynaecology OPDfor pain abdomen, menstrual disorders, white discharge per vaginum, incontinence urine, post coital bleeding, primary or secondary infertility were subjected for detailed pelvic examination, cytology, colposcopy and colposcopic directed punch biopsy.

A detailed clinical history of each patient was elicited which included complete history of present illness, past history,obstetric history and menstrual history, family history, medical history and her socioeconomic status, complaints of husband, profession of husband and extra marital relationship.

The patients were made to lie in dorsal lithotomy position and per speculum examination was done. After evaluating the cervix, Paps smear was taken for cytology with Ayers spatula from ectocervix after rotating at 360 degree and spread on 2 glass slides to prepare thin films and kept in koplin jar and sent for cytology reporting. The patients were then subjected to colposcopy and punch biopsy.

RESULTS: A total of 50 women were included in the study. Majority $(60 \%)$ of the patients participated in the study were from age group 21-30 years. Majority of the patients $(62 \%)$ had parity 3. Only $3.4 \%$ patients were nullipara. In our study most common presenting symptom seen was Vaginal discharge + itching vulva seen in $26(52 \%)$ of the patients, followed by Vaginal discharge +pain abdomen seen in $10(20 \%)$ of the patients. On per speculum examination $26(52 \%)$ of the patients showed hypertrophy followed by ectropion in $12(24 \%)$ of the patients, normal cervix was found in $6(12 \%)$ of the patients.

In our study Dyskaryosis was seen in $12(24 \%)$ of patients on cytology examination and $8(16 \%)$ on biopsy examination(table no.1). On colposcopic examination $8(16 \%)$ of the patients had grade 2 lesions (table no.2).

On comparison with biopsy cervix as gold standard for detection of CIN, cytology had shown Sensitivity - 57.14\%, Specificity - 88.88\%, NPV- 84.21\%, PPV - 66.66\%, Accuracy - 80 \% (table no.3). On comparison with biopsy cervix as gold standard for detection of CIN, colposcopy had shown Sensitivity - 80\%, Specificity - 80\%, NPV - 94.11\%, PPV - 50\%, Accuracy - 80\% (table no.4). 


\section{ORIGINAL ARTICLE}

DISCUSSION: The present study targets to compare the results cytology and Colposcopy for early detection of premalignant lesions of cervix. Results were statistically analyzed and sensitivity and specificity of cytology and colposcopy were evaluated.

In our study, $60 \%$ of patients were in the age group of 21-30 years, the sexually active reproductive age group and more prone to sexually transmitted infections. 52\% patients were Para $2,56 \%$ were residents of rural areas, $80 \%$ were Hindus, $60 \%$ were literate till $5^{\text {th }}$ standard, $92 \%$ were married, $56 \%$ had age of first intercourse between 15 -20years, $60 \%$ were in lower middle class, $40 \%$ were non users of contraception.

The study of Palefsky et al 1999 showed that higher number of previous pregnancies and younger age groups less than 30 years was associated with HPV infections. ${ }^{5}$ Risk factors for HPV infection in young women have primarily shown to reflect sexual activity including younger age, younger age at first intercourse, number of male sexual partners (Burk et al 1996; Bierman et al 1998; Bauer et al 1993; Moscicki et al 1990; Wheeler et al 1993.6

In our study, 52\% patients had vaginal discharge and itching, 52\% showed hypertrophy of cervix indicative of chronic infection of cervix.

In our study $12(24 \%)$ of patients had premalignant lesion of cervix in cytology with sensitivity of cytology with biopsy as gold standard was $57.14 \%$ and specificity was $88.88 \%$, positive predictive value was 66.66 , negative predictive value was $84.21 \%$, whereas in a study done by PetryMenon et al in germany 2003 showed sensitivity of cytology for detection of CIN2 was 43.5\%, specificity 98\%, positive predictive value 11.4 and negative predictive value $99.7 \% .^{7}$ In another study done by Malur PR, Desai BR, Dalal Anita et al in 2009 in Belgaum sensitivity of cytology with biopsy as gold standard was $41.66 \%$, specificity was $96.92 \%$, PPV was $86.21 \%$ and NPV was $79.26 \% .^{8}$

In our study $16(32 \%)$ patients showed grade 1 and 2 lesions in colposcopy with sensitivity of colposcopy with biopsy as gold standard was $80 \%$ and specificity was $80 \%$, negative predictive value was 94.11, positive predictive value was 50 and accuracy of $80 \%$. In a study done by Malur PR, Desai BR, Dalal Anita et al in 2009 in Belgaum sensitivity of colposcopy with biopsy as gold standard was $80 \%$, specificity was $81.54 \%$, PPV was $66.66 \%$ and NPV was $89.83 \% .{ }^{8}$ In another study of Lozowski et al sensitivity of colposcopy was $96 \%$ and specificity of $29 \%$ and Stewart et al study had sensitivity of $89 \%$ and specificity of $52 \% .9,10$

On biopsy, 8(16\%) patients had premalignant lesions so false positives were higher in colposcopy than cytology.

CONCLUSION: In developing countries like India with large population burden, cytology, a low cost and easily accessible test, is the most logical screening modality although it has very low sensitivity but detection rates could be further improved using liquid cytology and use of endocervicalcytobrush. Colposcopy with high sensitivity is although an important adjunctive screening modality but requires expertise and training for interpretation and is costly.

\section{REFERENCES:}

1. Sawaya GF, Brown AD, Washington AE and Garber AM. Clinical practice, Current approaches to cervical cancer screening. N Eng J Med 2001;344;1603-07. 
2. Wright TC Jr, Cox JT, Massad LS, Carlson J, Twigs LB and Wilkinson EJ. 2001 consensus guidelines for the management of women with cervical intraepithelial neoplasia. AM J Obstet Gynecol. 2003; 189:295-304.

3. Singh V,Sehgal A, Luthra UK. Screening for cervical cancer by direct inspection. Br Med J. 1992; 304; 534-5.

4. Walboomers, JMM, Jacobs MV, Manos MM, et al. Human papilloma virus is a necessary cause of invasive cervical cancer worldwide. J Pathol 1999; 189: 12-19.

5. Palefsky, JM, Howard Minkoff, Lesslie A.Cervicovaginal HPV infection in HIV -1 positive and high risk HIV negative women.Journal of national cancer institute,Vol. 91, no. 3, 226-236, Feb.1999.

6. Burk RD, HGY, Beardsley L, Bierman R.-Sexual behavior and partner characteristics are the predominant risk factors for genital human papilloma virus infection in young women.J. Infect Dis 1996; 174; 679-89.

7. Petry KU,Menton S et al. Inclusion of HPV testing in routine cervical cancer screening for women above 29 years of Germany; results for 8466 patients. Br.J.Cancer (2003) 88, 15701577.

8. Malur PR, Desai BR, Dalal Anita et al. Sequential screening with cytology and colposcopy in detection of cervical neoplasia. JSAFOG, Vol.1(3), Sep-Dec 2009:45-48.

9. Lozowski MS, Mishriki Y, Talebian F, et al. The combined use of cytology and colposcopy in enhancing diagnostic accuracy in preclinical lesions of the uterine cervix.ActaCytol. 1982; 26; 285-91.

10. Stewart L, Collins YC. Strength of correlations between colposcopic impression and biopsy histology. Gynecol oncol.2003; 89; 424-8.

\begin{tabular}{|l|c|c|}
\hline \multicolumn{1}{|c|}{ Findings } & $\begin{array}{c}\text { Cytology } \\
\text { n (\%) }\end{array}$ & $\begin{array}{c}\text { Biopsy } \\
\text { n (\%) }\end{array}$ \\
\hline No abnormality detected & $12(24)$ & $18(36)$ \\
\hline Inflammatory & $26(52)$ & $24(48)$ \\
\hline Dyskaryosis/ CIN & $12(24)$ & $08(16)$ \\
\hline Total & $\mathbf{5 0}$ & $\mathbf{5 0}$ \\
\hline
\end{tabular}

Table no. 1: Distribution of the patients according to the findings of cytology and biopsy.

*pap smears were evaluated by Bethesda system

\begin{tabular}{|c|c|c|}
\hline Colposcopy finding & Number of patients & Percentage \\
\hline No abnormality detected & 34 & 68 \\
\hline Grade 1 & 8 & 16 \\
\hline Grade 2 & 8 & 16 \\
\hline Grade 3 & - & - \\
\hline \multicolumn{2}{|c|}{ Table no. 2: Distribution of the patients } \\
according to the findings of colposcopy
\end{tabular}

*For colposcopy, Coppleson grading was followed 


\begin{tabular}{|c|c|c|c|}
\hline \multirow{2}{*}{ Cytology } & \multicolumn{2}{|c|}{ Biopsy } & \multirow{2}{*}{ Total(n=50) } \\
\cline { 2 - 4 } & Positive & Negative & \\
\hline Positive & 8 & 4 & 12 \\
\hline Negative & 6 & 32 & 38 \\
\hline Total & 14 & 36 & 50 \\
\hline
\end{tabular}

Table no. 3: Comparison of cytology with biopsy

cervix as gold standard for detection of CIN

Sensitivity - 57.14\%, Specificity - 88.88\%, NPV- 84.21\%, PPV - 66.66\%, Accuracy - 80\%

\begin{tabular}{|c|c|c|c|}
\hline \multirow{2}{*}{ Colposcopy } & \multicolumn{2}{|c|}{ Biopsy } & \multirow{2}{*}{ Total(n=50) } \\
\cline { 2 - 4 } & Positive & Negative & \\
\hline Positive & 8 & 8 & 16 \\
\hline Negative & 2 & 32 & 34 \\
\hline Total & 10 & 40 & 50 \\
\hline
\end{tabular}

Table no. 4: Comparison of colposcopy with biopsy as gold standard for detection of CIN

Sensitivity - 80\%, Specificity - 80\%, NPV - 94.11\%, PPV - 50\%, Accuracy - 80\%

\section{AUTHORS:}

1. S. Sharma

2. A. Sharma

3. U. Sinha

4. RoshanChanchlani

\section{PARTICULARS OF CONTRIBUTORS:}

1. Assistant Professor, Department of Obstetrics and Gynaecology, Chirayu Medical College and Hospital, Bhopal.

2. Assistant Professor, Department of Surgery, Chirayu Medical College and Hospital, Bhopal.

3. Associate Professor, Department of Community Medicine, Chirayu Medical College and Hospital, Bhopal.
4. Associate Professor, Department of Surgery, Chirayu Medical College and Hospital, Bhopal.

\section{NAME ADRRESS EMAIL ID OF THE}

\section{CORRESPONDING AUTHOR:}

Dr. RoshanChanchlani, 1/6-Idgah Kothi, Doctors Enclave, Near Filter Plant, Idgah Hills,

Bhopal, (M.P.) - 462001.

Email-roshanchanchlani@gmail.com

Date of Submission: 26/11/2013.

Date of Peer Review: 27/11/2013.

Date of Acceptance: 05/12/2013.

Date of Publishing: 10/12/2013 